Skidmore College

Creative Matter

Geosciences Faculty Scholarship

Geosciences

2009

\title{
Photodissolution and Other Photochemical Changes upon Irradiation of Algal Detritus
}

Lawrence L. Mayer

Linda L. Schick

Kathleen R. Hardy

Meg Estapa

Skidmore College

Follow this and additional works at: https://creativematter.skidmore.edu/geosci_fac_schol

Part of the Oceanography Commons

\section{Recommended Citation}

Mayer, L.M., L.L. Schick, K.R. Hardy, M. L. Estapa, 2009. Photodissolution and other photochemical changes upon irradiation of algal detritus. Limnology and Oceanography, 54: 1688-1698.

This Article is brought to you for free and open access by the Geosciences at Creative Matter. It has been accepted for inclusion in Geosciences Faculty Scholarship by an authorized administrator of Creative Matter. For more information, please contact jluo@skidmore.edu. 


\title{
Photodissolution and other photochemical changes upon irradiation of algal detritus
}

\author{
Lawrence M. Mayer, ${ }^{*}$ Linda L. Schick, Kathleen R. Hardy, and Margaret L. Estapa
}

School of Marine Sciences, Darling Marine Center, University of Maine, Walpole, Maine

\begin{abstract}
Several recent lines of literature point toward strong photoreactivity of phytoplanktonic detritus. We examined effects of irradiation of algal membrane fragments in various stages of decay, with emphasis on transfer of materials from solid to dissolved phase (photodissolution). After simulated solar irradiation for $24 \mathrm{~h}$, up to several tens of percent of particulate organic matter converted to photodissolved organic matter (PDOM). Prior microbial decay enhanced PDOM production. PDOM had initially high $\mathrm{C}: \mathrm{N}$ ratios, which decreased with irradiation time. Dissolved organic nitrogen dominated nitrogen photodissolution, followed by minor photoammonification and negligible nitrite plus nitrate production. Chromophoric particulate organic matter bleached at visible wavelengths and underwent dissolution, creation, and bleaching at ultraviolet (UV) wavelengths, resulting in net loss of color in particulates and net gain of largely UV-absorbing PDOM that also exhibited humic-type fluorescence. Solid phase proteinaceous material became less accessible to proteases after microbial decay but regained this accessibility upon irradiation. Irradiation under anoxic conditions roughly halved production of PDOM, including chromophores and humic fluorophores. Oxygen enhancement of these reactions, along with production of peroxides, implies a strong role for photosensitization. Pigments, unsaturated lipids, and tryptophan emerged as likely sources of reactive oxygen species. Lipid peroxides appeared as a reactive intermediate product. If these reactions in the ocean scale to pigment loss as found in our experiments, at least 5 $15 \%$ of particulate organic matter could undergo photodissolution before settling in some planktonic environments. This photodissolution would enhance remineralization by photic zone microbial communities and thus upper ocean elemental recycling.
\end{abstract}

Light has long been known to energize the creation of organic matter $(\mathrm{OM})$ in the ocean but is being increasingly appreciated also as an agent of destruction of this OM. Most emphasis in this latter role has been on photolysis of dissolved OM (DOM; Mopper et al. 1991; Osburn and Morris 2003), both via direct photooxidation and via the conversion of dissolved OM into compounds more readily degradable by bacteria (Moran and Zepp 1997). Recently, increasing attention is being paid to the role of light in the photodegradation of particulate OM (Zafiriou 2002). One such reaction that has been demonstrated for sedimentary organic matter is the dissolution of the particulate OM, termed "photodissolution" (Kieber et al. 2006; Mayer et al. 2006).

Photodissolution can convert up to tens of percent of sedimentary $\mathrm{OM}$ into the dissolved phase, in well-lit suspensions, in dozens of hours. Recently, we have found that the photodissolved OM (PDOM) from nearshore sediments has modern ${ }^{14} \mathrm{C}$ ages, despite average particulate $\mathrm{OM}$ ages of ca. $10^{3} \mathrm{yr}$ (Mayer et al. 2009). This finding suggests that relatively fresh planktonic detritus may be especially susceptible to photodissolution. Nelson (1993) suggested that phytodetritus might be a significant source for photochemically produced low-molecular weight organic matter. In terrestrial ecosystems, irradiation of fresh vascular plant detritus causes leaching of DOM from these substrates (Måns et al. 1998; Anesio et al. 1999), so that dissolution of fresh organic detritus deserves examination in marine systems.

\footnotetext{
*Corresponding author: Lmayer@maine.edu
}

Some photochemical changes have previously been observed in marine particulate detritus in planktonic zones. Photodegradation was early identified as a potentially important pathway for destruction of plant pigments (Lorenzen 1967; Soohoo and Kiefer 1982). Chemical marker studies in open ocean water columns confirmed extensive photoalteration of pigments in the photic zone (Cuny et al. 1999, 2002). Rontani (1998, 2001) demonstrated photochemical alteration of other lipid compounds in planktonic detritus, via detection of photoproducts such as lipid peroxides, and sediment trap studies have confirmed their importance (Marchand and Rontani 2001; Marchand et al. 2005). Some products of cellular lipid photodegradation are soluble organic compounds (North et al. 1994; Girotti 2001), providing at least one compound class that might serve as a source for PDOM.

It follows that fresh algal material and its microbially processed detritus should be tested for their susceptibility to photodissolution. We therefore examined this process and several other photochemical changes to algal detritus at various early stages of decay. We emphasized effects on bulk properties, especially the transfer of materials from the particulate to the dissolved phase, rather than on trace markers. Because some photochemical processes are considered to result from photosensitization, in which secondary reactive oxidants from primary photochemical events lead to further reactions, we tested for the role of oxygen.

\section{Methods}

We used the commercially available, green flagellate Tetraselmis sp. (strain 429; Reed Mariculture) as our 
experimental algae. This alga is not a common one in the oceans, but its biochemical composition - in terms of the content and composition of major compound classes - is similar to most common taxa (Brown 1991). To focus on dissolution of truly particulate phases, we removed dissolved, cytoplasmic materials by subjecting the algal slurries, as received, to $2 \mathrm{~min}$ of ultrasonication in an ice bath, centrifuging to remove the supernatant, and rinsing with deionized water followed by centrifugation for several cycles until the supernatant was clear. The precipitate of membrane-rich detritus was then freeze-dried, ground gently in a MicroMill, and stored frozen. We did not test for the influence of any of these processing steps on photochemical reactivity, with the exception of storage; up to $2 \mathrm{yr}$ storage of the freeze-dried membrane preparation had small impact on the results presented below.

Artificial seawater was made from deionized water, to which chloride and sulfate salts were added to a composition that contained appropriate amounts of $\mathrm{Na}, \mathrm{Mg}, \mathrm{Ca}$, $\mathrm{K}, \mathrm{Cl}$, and $\mathrm{SO}_{4}$.

We assessed the time course of photodissolution by irradiating $98.5 \mathrm{mg} \mathrm{L}^{-1}$ suspensions of Tetraselmis membrane detritus, which had been stored in a freeze-dried state for $2 \mathrm{yr}$, in artificial seawater. These suspensions were disaggregated by brief ultrasonication. Triplicate beakers of this suspension, for each time point, were covered with quartz plates and irradiated using a Suntest XLS+ that provides simulated sunlight with a total energy of $765 \mathrm{~W} \mathrm{~cm}^{-2}$ - similar to midday subtropical sunlight. Beakers in a shallow water bath, atop a magnetic, multiplace stir plate, were stirred constantly at a temperature of $20-22^{\circ} \mathrm{C}$, which was maintained by bathing the beakers in water from a cooling circulator. At $0,0.5,4$, and $24 \mathrm{~h}$, subsamples from the appropriate suspensions were removed by pipetting aliquots from stirred suspensions. Aliquots of these subsamples were then filtered through premuffled Whatman GFF filters. Dark controls were prepared similarly. With the methods described below, the filtrates were then analyzed for dissolved organic carbon (DOC), total dissolved nitrogen, ammonia, and spectral absorbance and fluorescence. Material caught on filters was analyzed for particulate organic carbon and nitrogen, chlorophyll, and pheopigments. Peroxides and spectral absorbance were measured on whole suspensions.

Two experiments tested for the effects of oxygen on photodissolution of freshly prepared algal membranes. In the first, two slurries with $100 \mathrm{mg}$ of membrane detritus $\mathrm{L}^{-1}$ were made - one bubbled with air and the other bubbled with $\mathrm{N}_{2}$ gas in a glove bag. Subsamples were placed in muffled quartz tubes with silicone stoppers and irradiated as above for $24 \mathrm{~h}$. At $t=0$ and $t=24 \mathrm{~h}$, replicate tubes were removed and $10-\mathrm{mL}$ filtered through premuffled Whatman GFF filters for particulate carbon and nitrogen and 40-mL filtered for enzymatically hydrolyzable amino acids (EHAA). Filtrates were analyzed for DOC, inorganic and organic nitrogen forms, and spectral absorbance and fluorescence.

The second experiment tested for the combination of roles of oxygen and early microbial decay on photochemical reactions. Algal detritus, as described above, was allowed to decay for periods of 2 weeks and 2 months. Freeze-dried membrane detritus ( $10 \mathrm{~g}$ in 5 liters of artificial seawater) was disaggregated by ultrasonication. To represent fresh algae, an aliquot was immediately centrifuged (20 min at 12,000 revolutions per minute), and the precipitate was then freeze-dried and used for the fresh membrane treatment. The rest of the suspension was inoculated with bacteria, using $100 \mu \mathrm{L}$ of a supernatant from an ultrasonicated and then settled suspension of sediment that had been freshly collected in the Damariscotta estuary (Maine). The algal suspension was then incubated in a flask with a cotton plug in its mouth for 2 weeks in the dark on a reciprocal shaker. An aliquot of this suspension was then centrifuged, and the precipitate was freeze-dried and used for the $t=2$ week treatment. The remaining suspension was further incubated for another 6 weeks, centrifuged, and freeze-dried as above, and used for the $t=2$ month treatment. All freeze-dried, decay treatments were stored in a $-20^{\circ} \mathrm{C}$ freezer until the irradiation experiment.

These fresh and decayed detritus treatments were then subjected to simultaneous irradiation under aerobic and anaerobic conditions. For each decay state, 60 -mg aliquots of freeze-dried detritus were placed into two large beakers, and $600 \mathrm{~mL}$ of artificial seawater was added. One beaker was bubbled with air and the other with $\mathrm{N}_{2}$ gas (in a glove bag) for $0.5 \mathrm{~h}$. Aliquots of each suspension were then pipetted into $90-\mathrm{mL}$ quartz tubes and closed with silicone stoppers, removing excess gas with a syringe to promote snug closure. Triplicate samples of each suspension were also removed for various analyses of the preirradiated states. After $24 \mathrm{~h}$ irradiation in the Suntest at $20-22^{\circ} \mathrm{C}$, material for measurement on particulate phases was obtained by filtering $40 \mathrm{~mL}$ for EHAA analysis, $10 \mathrm{~mL}$ for POC and particulate nitrogen analysis, $10 \mathrm{~mL}$ for particulate total hydrolyzable amino acids (THAA) analysis, and $10 \mathrm{~mL}$ for pigment analysis. All filtrations were through GFF filters. The filtrates were subjected to analysis for DOC, total dissolved nitrogen, ammonia, and nitrite plus nitrate.

Analyses-Particulate organic carbon (POC) and particulate nitrogen on filters were analyzed on a Perkin-Elmer 2400B Elemental Analyzer. Chlorophyll and pheopigments on filters were analyzed spectrophotometrically on acetone extracts before and after acidification (methods 4.1 and 4.2 in Parsons et al. 1984). Particulate THAA were measured by hydrolyzing the filters in $6 \mathrm{~N} \mathrm{HCl}$ under $\mathrm{N}_{2}$ at $110^{\circ} \mathrm{C}$ for $24 \mathrm{~h}$, followed by measuring the amino acid monomers fluorometrically with orthophthaldialdehyde (OPA) as in Mayer et al. (1995). EHAA on filters were measured using the method of Mayer et al. (1995), which involves incubation with proteolytic enzymes followed by precipitation of high-molecular weight material, acid hydrolysis (6 $\mathrm{N} \mathrm{HCl}$ under $\mathrm{N}_{2}$ at $110^{\circ} \mathrm{C}$ for $24 \mathrm{~h}$ ) of the low-molecular weight fraction, and measurement of hydrolyzed amino acid monomers by OPA fluorescence as above.

Filtrates were analyzed for DOC using either a Shimadzu 5000A total organic carbon (TOC) analyzer or $\mathrm{DOC}$ and total dissolved nitrogen using a TOC-V CPH 
analyzer with a total nitrogen module (TNM-1). For DOC we used the nonpurgeable organic carbon method, after verifying its agreement with the total carbon minus dissolved inorganic carbon (TC - DIC) method, as per manufacturer's instructions. DIC concentrations were measured by sparging acidified samples on the Shimadzu analyzers. Ammonium concentrations in filtrates were determined spectrophotometrically either on a Hitachi U-3000 spectrophotometer or on a Lachat QuikChem FIA+ analyzer. In either case, we used the alkaline, phenolhypochlorite spectrophotometric method as described in the Lachat instrument manual (method No. 31-107-06-1B). The sum of nitrite and nitrate concentrations was measured on the Lachat analyzer using cadmium reduction of nitrate to nitrite, followed by spectrophotometric determination of the diazo dye formed with sulfanilamide (method No. 31-107-04-1-C). Some total dissolved nitrogen measurements were performed on the Lachat instrument, using the nitrate plus nitrite method above after a heated alkaline persulfate-UV digestion using the Lachat preparation module (method No. 31-107-04-3-A). Intercalibrations for total dissolved nitrogen between the Lachat and Shimadzu instruments yielded excellent agreement. Dissolved organic nitrogen (DON) was calculated as total dissolved nitrogen minus inorganic nitrogen forms. Dissolved peroxide concentrations were measured on whole suspensions to avoid decomposition of labile peroxides during filtration. They were measured by the fluorometric p-hydroxyphenyl acetic acid (POHPAA) dimerization method of Miller and Kester (1988), adapted for use with a BMG-Labtechnologies Fluostar microplate reader. This method has been shown to detect both hydrogen peroxide and some organic peroxides.

Light absorbance and fluorescence of filtrates and unfiltered suspensions were analyzed. Absorbance of filtrates was scanned in a Hitachi U-3000 double-beam spectrophotometer, referenced to artificial seawater. Excitation-emission scans of fluorescence of filtrates were run on a Hitachi F-4500 spectrofluorometer and are corrected for instrumental parameters. Suspensions containing scattering particulates were scanned for absorbance in a $15-\mathrm{cm}$ Labsphere integrating sphere with center-mounted cuvette on a Cary 300 spectrophotometer (Babin and Stramski 2002). Absorption coefficients were calculated from absorbance spectra as

$$
a(\lambda)=\frac{2.303 \cdot A(\lambda)}{l}
$$

where $a\left(\mathrm{~m}^{-1}\right)$ is the absorption coefficient, $A$ is the absorbance, and $l(\mathrm{~m})$ is the cuvette pathlength. Filtrate absorption spectra were corrected for small amounts of scattering $\left(a(800) \sim 0.01 \mathrm{~m}^{-1}\right)$ by subtraction of a flat baseline. Suspensions containing particulates did not require correction for scattering $\left(a(800)<0.005 \mathrm{~m}^{-1}\right)$ because the geometry of the integrating sphere permitted detection of all scattered light. Solid phase absorption spectra were calculated as total suspension absorption spectra minus filtrate absorption spectra as described above. Filtrate absorption spectra were iteratively fit to the single-exponential model $\left(a(\lambda)=a(500) e^{-S(\lambda-500)}\right)$ over the wavelength range $300-800 \mathrm{~nm}$ to obtain spectral slopes $(S)$.

Significance for comparisons among treatment values is based on $95 \%$ confidence intervals from $t$-tests. We have propagated errors when comparing ratios of parameter values.

\section{Results}

Kinetics - The kinetics experiment with undecayed Tetraselmis membranes demonstrated strong photodissolution and other chemical changes over $24 \mathrm{~h}$. Under irradiation, DOC quickly formed from the particulate phase and then slowed its appearance (Fig. 1a), reaching 19\% of the initial POC by 24 h. Dark controls, whether stirred or unstirred, exhibited dissolution or desorption of $1.2 \%$ or less of initial POC. Particulate nitrogen photodissolved in similar fashion, largely appearing as DON (Fig. 1b). The C: $\mathrm{N}$ ratios of the PDOM, calculated as the ratio of incremental increases in DOC and DON, progressively decreased, from an initial value of 78 at $0.5 \mathrm{~h}$ to 11 between $0.5 \mathrm{~h}$ and $4 \mathrm{~h}$, and finally to 8.8 between $4 \mathrm{~h}$ and $24 \mathrm{~h}$-averaging 11.3 over the $24 \mathrm{~h}$. Light-enhanced release of ammonium"photoammonification"-accounted for $12 \%$ of the total photodissolved nitrogen production at $24 \mathrm{~h}$, in contrast to dark control ammonification of $0.5 \%$ of total desorbed nitrogen (Fig. 1b). The proportion of total dissolved nitrogen that appeared as ammonium decreased with time. Dissolved peroxides appeared in the aqueous phase with similar kinetics as the carbon and nitrogen forms (Fig. 1c). In this and other experiments, there were persistent losses of several percent of the initial total OC, similar to those reported for sediment irradiations by Mayer et al. (2006). Separate experiments in sealed tubes found oxidation of $\sim 1.2 \%$ of the algal organic carbon (DOC + POC) to inorganic carbon (M. Estapa unpubl. data).

Chlorophyll largely disappeared by $4 \mathrm{~h}$ (Fig. 1d), consistent with studies such as Nelson (1993, and references therein), though use of different light sources prevents quantitative comparisons. Pheopigments increased slightly at $0.5 \mathrm{~h}$, but then also disappeared by $24 \mathrm{~h}$. Nelson (1993) also found pheopigments to degrade in a similar fashion as chlorophyll.

Changes in optical properties of these materials are consistent with the chemical changes. A small but significant amount of colored dissolved organic matter (CDOM) desorbed in the dark control; because there was no significant change in total suspension absorption, we calculate a small but significant decrease in particulate absorption. Under irradiation, pigment losses described above were reflected by complete loss of absorbance at visible wavelengths in the absorption spectra of the whole suspensions (Fig. 2a, d), which were dominated throughout the time course by the particulate phase (Fig. 2b). These results are similar to those of Nelson and Robertson (1993). UV absorption, on the other hand, generally increased for the whole suspension and was dominated by accumulation of UV-absorbing CDOM in the dissolved phase (Fig. 2a), while the particulate phase photobleached (Fig. 2b). This CDOM, formed either by photodissolution of UV-absorbing materials or formation of chromophores in the solution phase, reached peak 

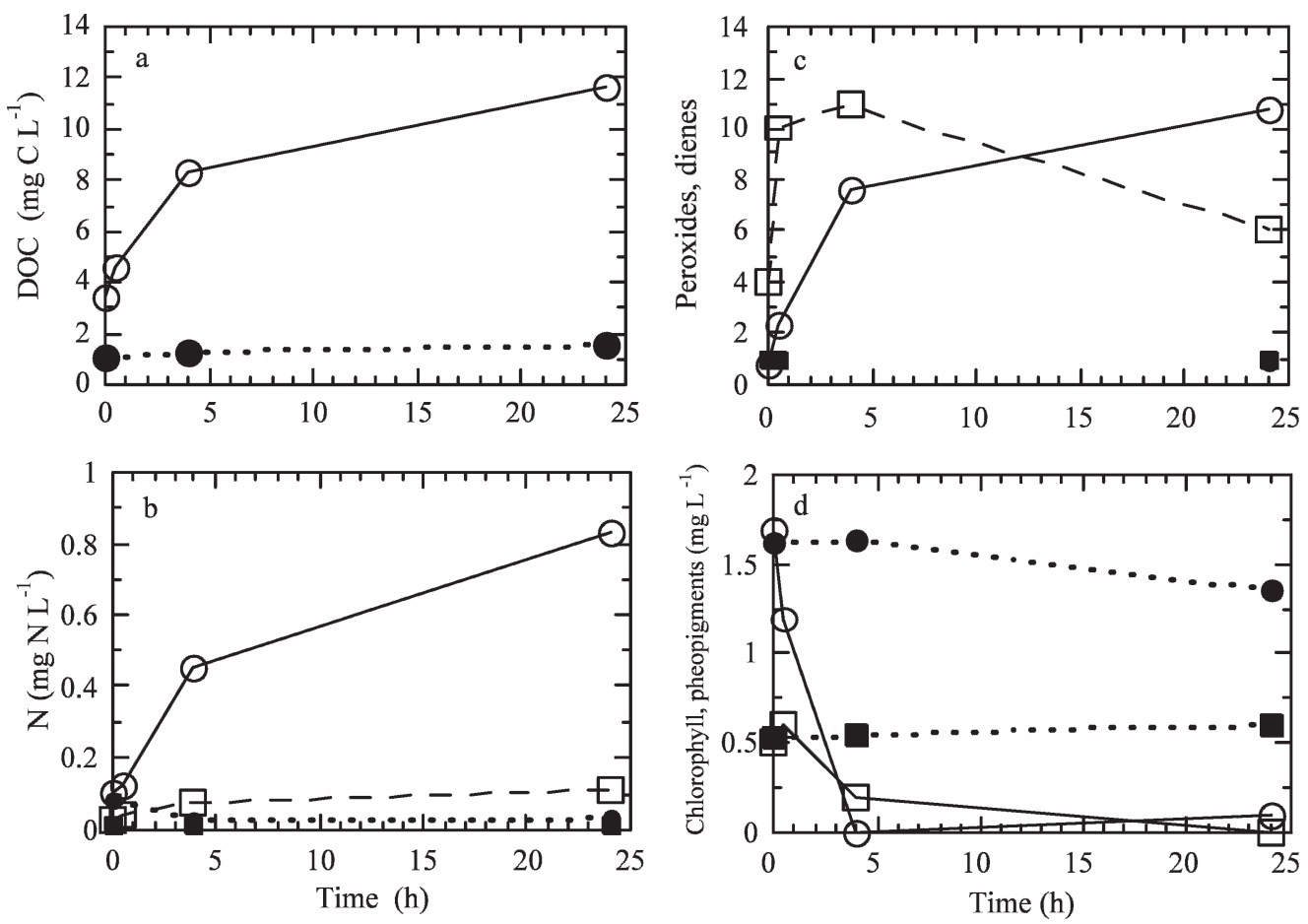

Fig. 1. Kinetics experiment results, plotted vs. time (h): (a) DOC (mg C L $\left.{ }^{-1}\right)$, (b) DON (circles) and ammonium-N (squares) $\left(\mathrm{mg} \mathrm{N} \mathrm{L}^{-1}\right.$ ), (c) dissolved peroxides (circles, $\mu \mathrm{mol} \mathrm{L}^{-1}$, using $\mathrm{H}_{2} \mathrm{O}_{2}$ as a standard) and dissolved conjugated dienes (squares, units are arbitrary peak heights), and (d) chlorophyll (circles) and pheopigments (squares) (mg L ${ }^{-1}$ ). Open circles are irradiated and closed circles are dark controls.

intensity at $4 \mathrm{~h}$ and then photobleached somewhat by $24 \mathrm{~h}$. Spectral slopes for the CDOM ranged from 0.018 to $0.023 \mathrm{~nm}^{-1}$ over the experiment, with small but nonsignificant differences among time points. These values are similar to those found in the ocean (Green and Blough 1994). Appearance of similar UV-absorbing material in the dissolved phase of irradiated algal suspensions has been previously observed (Yentsch and Reichert 1962).

In our experiment the UV spectra of the suspensions were marked by major peaks around $235 \mathrm{~nm}$ and $280 \mathrm{~nm}$ (Fig. 2). The $235-\mathrm{nm}$ peak provides evidence for the presence of conjugated dienes, which result from peroxidation of polyunsaturated lipids (Verhagen et al. 1977); this spectral peak has been used frequently to detect and, with suitable standards, quantitate these compounds (Corongiu and Milia 1983; Blokhina et al. 1999). Their presence at the beginning of the experiment implies autooxidation of the lipid-rich membranes during freeze-drying and/or storage prior to the experiment, a problem common in lipid oxidation studies and food storage (Corongiu and Milia 1983; López-Ayerra et al. 1998; Kanias et al. 2007). The relative concentrations of dienes were measured using valley-to-peak heights between ca. $235 \mathrm{~nm}$ and $254 \mathrm{~nm}$ of the second derivative plots of the absorbance scans; these heights follow Beers Law and are thus proportional to diene concentration (Corongiu and Milia 1983). This measure, applied to the dissolved phase spectra, increased over the first $4 \mathrm{~h}$ and then decreased by $24 \mathrm{~h}$ (Fig. 1c). The overall suspension (Fig. 2c) showed a clear increase in diene concentrations during the initial $4 \mathrm{~h}$, implying photochemical formation. The diene peak decreased in the particulate phase (Fig. 2b) while increasing in the dissolved phase up to $4 \mathrm{~h}$, implying some combination of bleaching on, and dissolution from, the solid phase for these compounds. Lipid peroxides are more hydrophilic than their precursor lipids, so that appearance in the dissolved phase is not unusual (Girotti 2001). Their decrease between $4 \mathrm{~h}$ and $24 \mathrm{~h}$ (Figs. 1, 2) is consistent with their instability under further irradiation (Frankel 1998). The POHPAA peroxide assay we used can detect hydrogen peroxide and at least some organic peroxides, though the range of detectable organic peroxides has not been well studied. Assuming a typical extinction coefficient of $25,000 \mathrm{~L} \mathrm{~mol}^{-1} \mathrm{~cm}^{-1}$ for conjugated dienes that indicate lipid hydroperoxides (Verhagen et al. 1977), the peak heights at $235 \mathrm{~nm}$ imply that such compounds might account for a significant fraction of the total peroxide concentrations measured by the POHPAA method at the 0.5 and $4 \mathrm{~h}$ time points, but not at the $24 \mathrm{~h}$ time point. Lipid peroxides derived from monounsaturated fatty acids have been found resulting from irradiation of phytoplankton (reviewed in Rontani 2001). The spectrophotometric assay used here may extend their findings to those from polyunsaturated compounds.

The broader and more complex peak around 270$285 \mathrm{~nm}$ was likely a mixture of proteinaceous material and conjugated trienes (Blokhina et al. 1999). This peak largely disappeared by $24 \mathrm{~h}$ into the emerging, broad background, UV absorption.

Fluorescent dissolved organic matter (FDOM, data not shown) showed proteinaceous material, indicated by tyrosine $\left(\lambda_{\mathrm{ex}}=220 \mathrm{~nm}\right.$ and $\left.\lambda_{\mathrm{em}}=300 \mathrm{~nm}\right)$ and lesser 


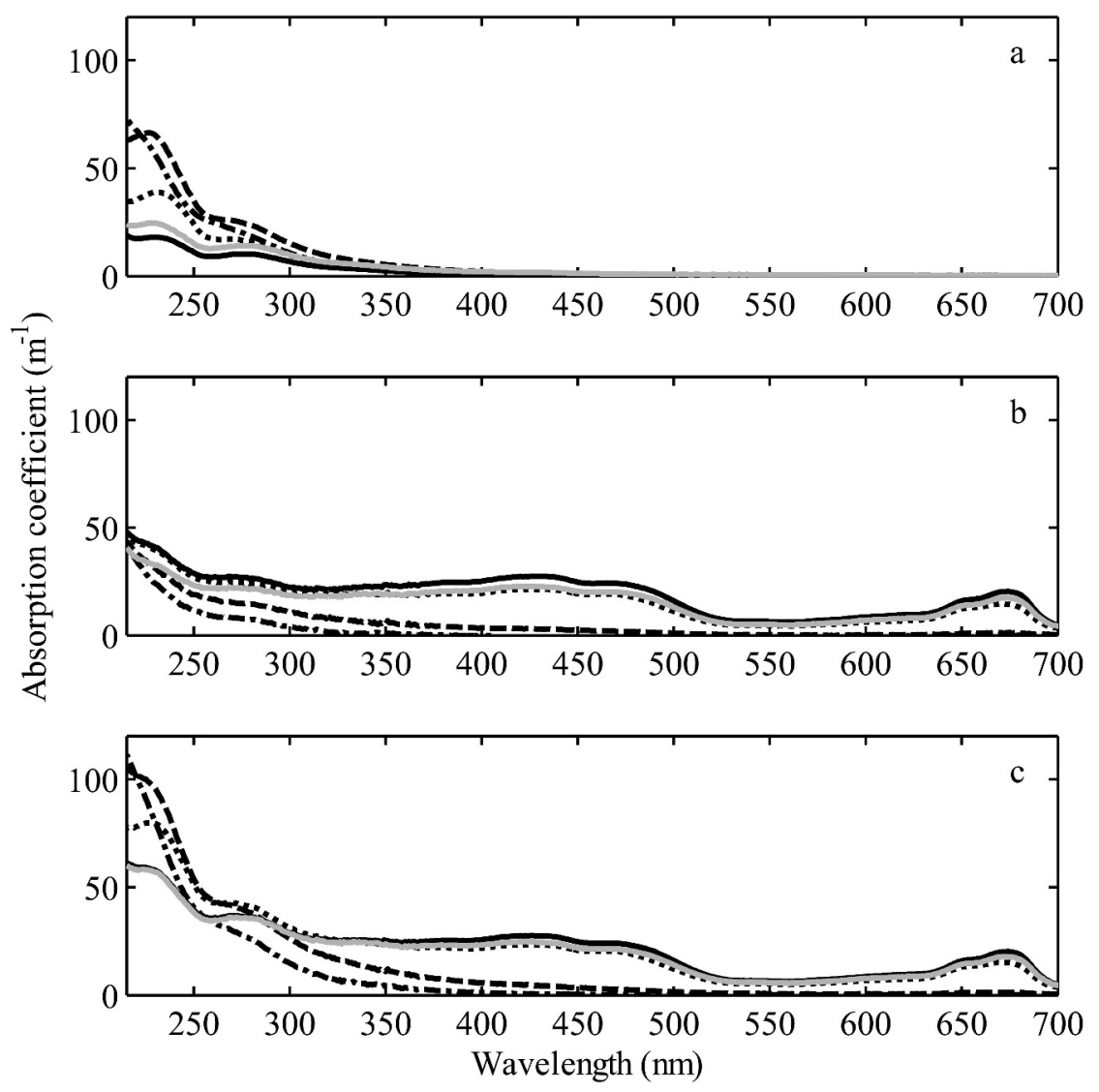

Fig. 2. Spectral changes during kinetics experiment: (a) dissolved fraction, (b) particulate fraction, and (c) unfiltered suspension. Solid line is $t=0$ (sometimes hidden under gray line), short dashed line is $t=0.5 \mathrm{~h}$, longer dash line is $t=4 \mathrm{~h}$, alternating dash line is $t=24 \mathrm{~h}$, and gray line is dark control after $24 \mathrm{~h}$.

tryptophan $\left(\lambda_{\mathrm{ex}}=220 \mathrm{~nm}\right.$ and $\left.\lambda_{\mathrm{em}}=340 \mathrm{~nm}\right)$ peaks (Mayer et al. 1999) throughout the experiment, but the data were too noisy to establish any temporal trends and may indicate trace contamination. Humic-type fluorescence appeared in solution during the irradiation with similar kinetics as other PDOM (Fig. 1a, b), reaching a plateau after $4 \mathrm{~h}$. The principal peak during the first $4 \mathrm{~h}$ was centered at $\lambda_{\mathrm{ex}}=345 \mathrm{~nm}$ and $\lambda_{\mathrm{em}}=440 \mathrm{~nm}$, but this peak was overtaken at the $24 \mathrm{~h}$ time point by one centered at $\lambda_{\mathrm{ex}}$ $=315 \mathrm{~nm}$ and $\lambda_{\mathrm{em}}=410 \mathrm{~nm}$.

Effects of decay and oxygen-To test for the effects of oxygen and of prior microbial decay of algal detritus on susceptibility to photochemical changes, we irradiated membranes in fresh vs. decayed states that had lasted 2 weeks and 2 months, under oxic and anoxic conditions. The particulate $\mathrm{C}: \mathrm{N}$ ratio was similar among decay treatments, ranging from 5.8 to 6.7 (Table 1). Total amino acid-nitrogen (THAA-N = THAA/6) also remained roughly constant, making up $81-87 \%$ of total particulate nitrogen (Table 1, Fig. 3b). The fraction of total amino acids available to enzymatic hydrolysis by proteases (EHAA : THAA), however, decreased strongly from 0.63 in fresh membranes to $0.34-0.38$ in the decayed detritus (Fig. 3c). Chlorophyll concentrations likewise decreased, roughly halving over the decay series (Table 1).

Upon irradiation, these different decay states of algal detritus displayed more variation in behavior (Table 1; Fig. 3). The decayed detritus showed greater production of PDOM, as both DOC and especially DON, than the fresh membranes. This increased production was enhanced about threefold under air relative to $\mathrm{N}_{2}$. The $\mathrm{C}: \mathrm{N}$ ratios of this PDOM were almost always higher than the original particulate detritus, except for the 2-month decayed detritus irradiated under $\mathrm{N}_{2}$. The $\mathrm{C}: \mathrm{N}$ ratios of PDOM derived from irradiated fresh membranes were especially high and became progressively lower from irradiated detritus subjected to prior microbial decay (Table 1; Fig. 3a). $\mathrm{C}: \mathrm{N}$ ratios of PDOM were always higher after irradiation under air than under $\mathrm{N}_{2}$. Particulate THAA values generally decreased upon irradiation along with total particulate nitrogen, leading to similar THAA-N : PN ratios (Fig. 3b). This ratio increased, however, for the two decayed treatments upon irradiation under oxic conditions, suggesting either preferential photodissolution of nonprotein materials or exposure of previously unavailable peptide bonds to acid hydrolysis. The accessibility of these amino acids to enzymatic hydrolysis increased after irradiation for most treatments but, similar to the THAA-N : PN results, 
Table 1. Analyses from detritus decay series irradiated under oxic and anoxic conditions. Parameters are particulate organic carbon (POC), particulate nitrogen (PN), dissolved organic carbon (DOC), dissolved organic nitrogen (DON), ammonium $\left(\mathrm{NH}_{4}\right)$, nitrite plus nitrate (NOx), enzymatically hydrolyzable amino acids (EHAA), total particulate amino acids (THAA), chlorophyll (CHL), and pheopigments (PHEO). Concentration units are the tabulated masses per liter of suspension.

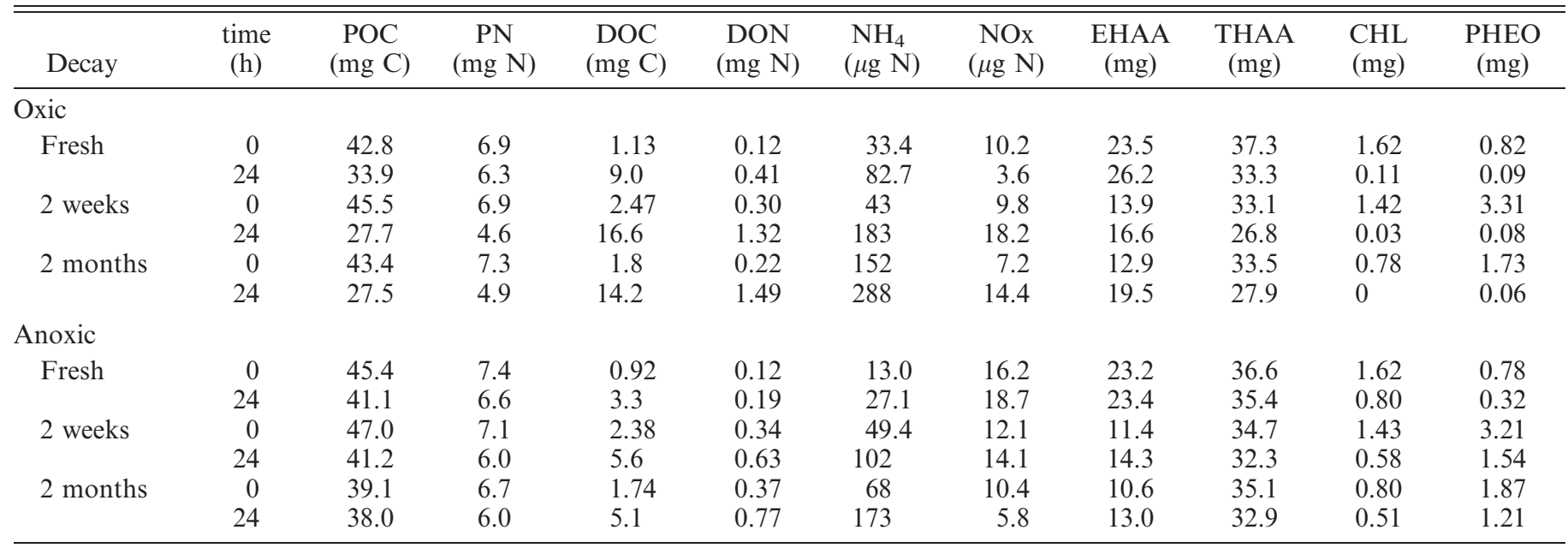

was most pronounced for decayed detritus irradiated under oxic conditions (Table 1, Fig. 3c). The 2-month detritus under oxic conditions, for example, increased its EHAA: THAA ratio from an initial 0.38 to 0.70 upon irradiation, essentially reversing the decrease in this ratio during the decay process. These changes in enzyme hydrolyzability thus magnify the smaller changes seen in acid hydrolyzability (Fig. 3b). Photoammonification followed overall nitrogen photodissolution, accounting for $12-19 \%$ of total nitrogen release with no consistent differences between oxic vs. anoxic conditions or with decay state of the detritus (Fig. 3d). Nitrate plus nitrite showed very small losses and gains, with no consistent pattern (Table 1). Last, chlorophyll and pheopigments essentially disappeared upon oxic irradiation of the $t=0$ and $t=2$-week treatments, as in the kinetics experiment (above), but lost only 36-60\% of initial values under anoxic irradiation (Table 1). This dependence of pigment degradation on oxygen was also observed by Nelson (1993).

The second experiment tested for the effect of oxygen on fresh membrane detritus only, measured many of the same parameters measured above, and gave similar results for POC, particulate nitrogen, EHAA, DOC, DON, ammonium, and nitrite plus nitrate (data not shown). In addition, this experiment examined the production of CDOM and FDOM, with similar results to those described in the kinetics experiment (see above) for the $24 \mathrm{~h}$ time point. CDOM production was also found in the anoxic irradiation, but with considerably less intensity than that from the oxic irradiations (data not shown). Solid phase optical absorption was not measured in this experiment. Changes in FDOM spectra also occurred (Fig. 4). The protein fluorescence peaks consisted of both tyrosine and tryptophan peaks before irradiation (Fig. 4a), but only tyrosine peaks remained after irradiation under both oxic and anoxic conditions (Fig. 4b). Tryptophan is well known as a photolabile compound and is sensitive under both oxic and anoxic conditions (Dillon and Spector 1980). The higher wavelength, humic fluorescence peak was found in all four replicates irradiated under oxic conditions and was again centered at $\lambda_{\mathrm{ex}}=315 \mathrm{~nm}$ and $\lambda_{\mathrm{em}}=410 \mathrm{~nm}$ (Fig. 4b). Under anoxic irradiation there was no production of this humic FDOM in three of the four replicates, and the fourth showed a peak at $\lambda_{\mathrm{ex}}=315 \mathrm{~nm}$ and $\lambda_{\mathrm{em}}=410 \mathrm{~nm}$ that was lower in intensity than those in the oxic irradiation treatments.

\section{Discussion}

Light-induced changes in nature of algal detritus-Dark controls in photochemical experiments involving biologically labile materials are problematic because both bacteria and light can cause oxidative and nonoxidative dissolution, while light affects the ability of bacteria to perform these functions (Sommaruga et al. 1997). Unlike studies with DOM, bacteria cannot be filtered out of these experiments, and there are no adequate poisons that convincingly eliminate bacterial activity and remain photochemically neutral (Zafiriou 2002). Thus, our dark control experiments are not intended to isolate a bacterial component of the various reactions studied under irradiation; rather, they serve only to demonstrate that these reactions would occur much less frequently without light. We found order-ofmagnitude increases in these various reactions when light was present. It's quite possible that some portion of these increases were due to enhanced bacterial activity acting on materials liberated by purely photochemical reactions as found in DOM photolysis experiments (Moran and Zepp 1997), even though light with the spectral quality and intensity used here can inhibit microbial activity (Sommaruga et al. 1997). Furthermore, separate experiments on the biodegradability of the PDOM from Tetraselmis, to which microbial inocula were added, showed half-lives of on the order of days (L. Mayer unpubl. data), so that it is unlikely that bacteria affected the photochemical reactions within $24 \mathrm{~h}$ to a major degree. Thus, the results from our 

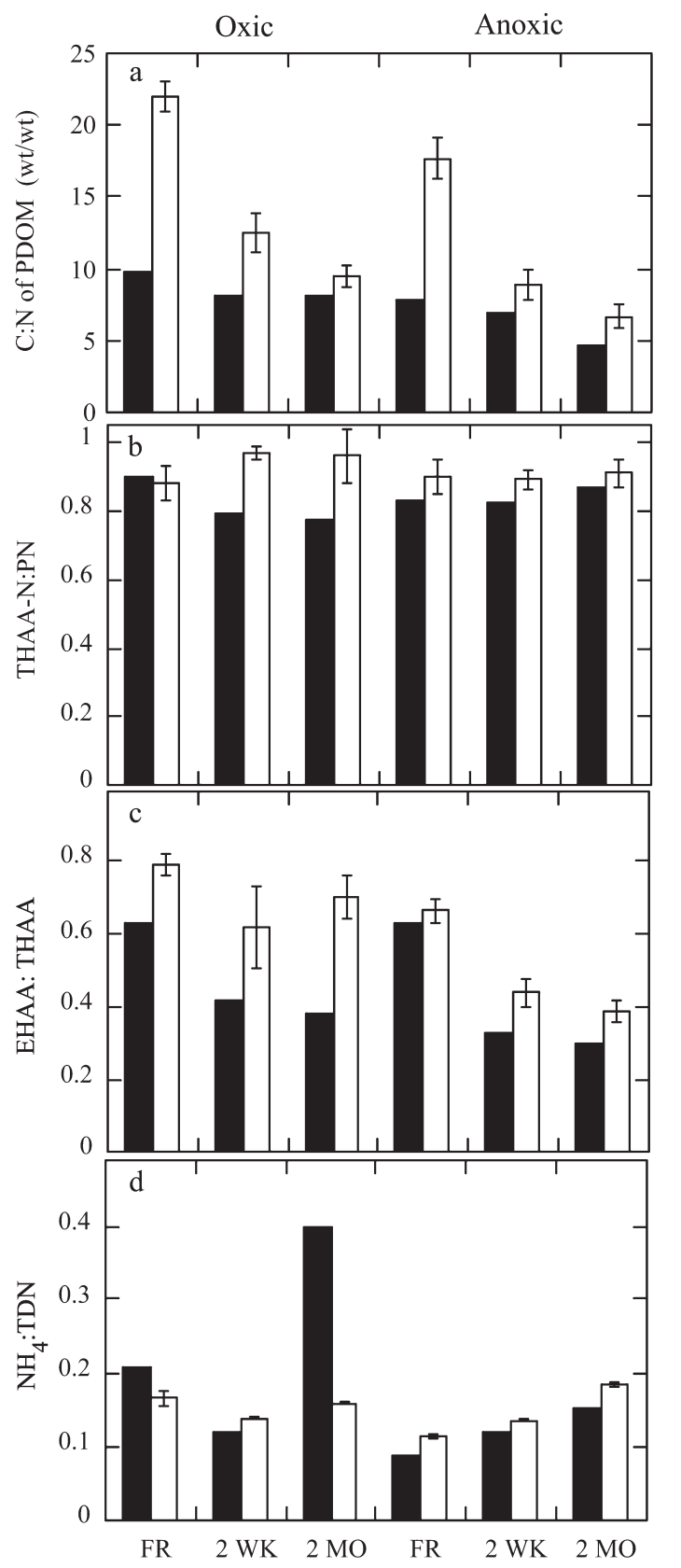

Fig. 3. Compositional changes upon irradiation of decay series. Parameters shown include (a) C: N of PDOM, (b) fraction of total particulate nitrogen analyzed as acid-hydrolyzed amino acids (THAA-N : PN), (c) fraction of acid-hydrolyzed amino acids that are hydrolysable by enzymes (EHAA:THAA), and (d) fraction of total dissolved nitrogen found as ammonium $\left(\mathrm{NH}_{4}: \mathrm{TDN}\right)$. Black bars are at beginning of irradiation and white bars are after $24 \mathrm{~h}$ of irradiation. Three pairs of bars are the fresh membrane detritus (FR), detritus aged for 2 weeks (2 WK), and detritus aged for 2 months ( $2 \mathrm{MO}$ ), each irradiated under oxic (left) and anoxic (right) conditions. Error bars on the 24-h irradiated treatments are standard deviations on treatment replicates. Comparisons among treatments in the text assume equal variance for $t=0$ and irradiated samples. irradiation treatments should be regarded as light-enhanced processes rather than purely photochemical reactions, although photochemical processes likely dominate.

Our principal finding is that young organic matter, as either fresh phytodetritus or early microbially reprocessed detritus, is indeed vulnerable to significant photodissolution upon irradiation. As much as $39 \%$ of the particulate $\mathrm{OM}$ dissolved over $24 \mathrm{~h}$ under aerobic irradiation conditions, with almost all of that converted to PDOM. This reaction is much more significant than photoremineralization; photooxidation of $\sim 1 \%$ of POC and photoammonification of $<1 \%$ of particulate nitrogen represented minor transformations of these elements.

Our experiments were conducted at high detritus concentrations of $\sim 100 \mathrm{mg} \mathrm{L}^{-1}$ in artificial seawater, with one algal type and an artificial detritus preparation protocol. Any of these conditions may affect the applicability of our results to field conditions, and each is an area for further study. Nevertheless, our experiments implicate various processes that may affect algal debris that is subjected to strong sunlight in the ocean.

Greater photodissolution occurred after microbial decay, which may indicate that microbially generated material (biomass and necromass) or humified organic matter generated during this decay is inherently more photolabile. It is also possible that microbial communities developed during the dark decay step caused dissolution of particulate organic matter during irradiation. The increase in efficiency of photoammonification with oxygen in the aged detritus $(\sim 0.2 \%$ of initial particulate nitrogen in fresh membranes to $1.5 \%$ of particulate nitrogen in the $t=2$ month treatment) may result from development of humified material during the irradiation. Tarr et al. (2001) showed that Suwannee River humic acid plus amino acids photoammonified more effectively than either substrate alone.

Alternatively, this increase in photodissolution upon decay of the original algal membranes may result from photosensitization due to partial destruction of biochemical assemblies that protect photolabile compounds from producing reactive oxygen species (ROS) (Rontani 2001). Oxidative attack on algal detritus can stimulate dissolution of organic matter in addition to remineralization reactions; for example, ozonation of phytoplankton in sanitary engineering studies leads to partial dissolution of algae (Hammes et al. 2007). Production of ROS, such as the peroxides found in our kinetics experiment, is consistent with the consumption of oxygen well in excess of that needed for photooxidation to DIC (M. Estapa unpubl. data). Photosensitization - the continuance of oxidative reactions by ROS - has long been suggested to be important in marine matrices (Zafiriou 1977; Nelson 1993; Rontani 2001). The enhancement by oxygen of photodissolution and of pigment photodegradation (Nelson 1993; this study) implicates photosensitization in our experiments. Algal membranes can serve as rich sources of ROS for photosensitization, via compounds such as chlorophyll, proteins, and unsaturated lipids.

The microbial processing of chloroplasts in our decay pretreatments, as evidenced by increases in the pheophytin: 


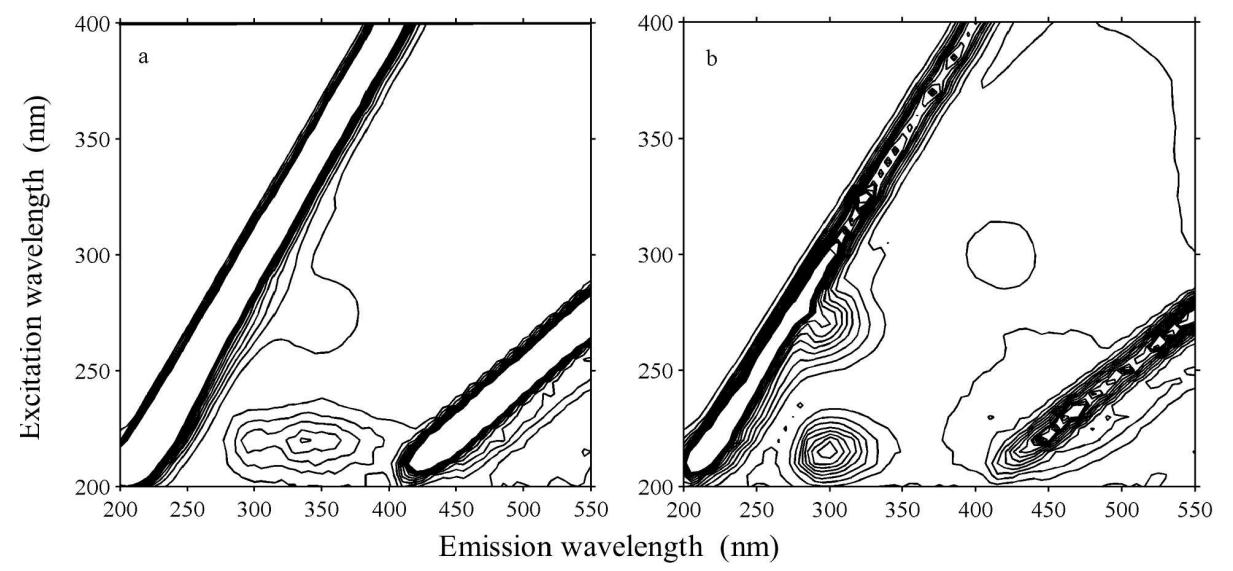

Fig. 4. Excitation-emission plots of dissolved fluorophores from the (a) $t=0$ nonirradiated and (b) $t=24 \mathrm{~h}$ irradiated treatments of Tetraselmis membranes. The tyrosine peak is at $\lambda_{\mathrm{ex}}=$ $220 \mathrm{~nm}$ and $\lambda_{\mathrm{em}}=300 \mathrm{~nm}$, tryptophan is at $\lambda_{\mathrm{ex}}=220 \mathrm{~nm}$ and $\lambda_{\mathrm{em}}=340 \mathrm{~nm}$, and the humic peak shown here is at $\lambda_{\mathrm{ex}}=315 \mathrm{~nm}$ and $\lambda_{\mathrm{em}}=410 \mathrm{~nm}$.

chlorophyll ratio (Table 1), likely degraded nondestructive pathways that channel absorbed light energy in vivo (Zafiriou 2002), so that a greater proportion of absorbed energy would lead to production of ROS (Rontani 2001). Hydrogen peroxide is produced by irradiation of broken chloroplasts (Robinson et al. 1980). Heath and Packer (1968) found production of lipid peroxides after irradiation of chloroplasts at levels that overloaded normal energy channeling pathways; the threshold light flux for such overloading would be expected to decrease upon microbial decay.

Proteins may provide another source of ROS. Tryptophan and its photochemical products such as n-formylkynurenine are quite photolabile (Creed 1984), and their degradation pathways have been extensively studied in matrices exposed to light, such as eyes or wool. They are potent photochemical sources of ROS such as hydrogen peroxide and superoxide ions (Inoue et al. 1982). The reduction of dissolved protein fluorescence in our experiments suggests that similar photolysis occurred in the solid phase; photolysis in either phase would initiate the degradation pathways that spin off various ROS. Products of tryptophan photolysis also commonly interact with other compounds (Creed 1984).

Lipid peroxides imply organic ROS derived from unsaturated lipids and can serve as reactive intermediates for further oxidation reactions (Frankel 1998; Rontani 2001). They are also vulnerable to condensation reactions with other compounds, including lipids (Marchand and Rontani 2001) and other compound classes (e.g., Refsgaard et al. 2000). Both lipid peroxides and the aldehydes that can form from them (Rontani 2001) can link with free amine groups or ammonia to form fluorescent products (Kieber et al. 1997; Kikugawa and Beppu 1987). Kikugawa et al. (1991) found the same two fluorescent peaks that we observed via such conjugations. In their work the peak at $\lambda_{\mathrm{ex}}=315 \mathrm{~nm}$ and $\lambda_{\mathrm{em}}=410 \mathrm{~nm}$ represented dityrosine, which formed via reactions with free radicals derived from lipid peroxides, and in this sense lipid peroxides may also serve as long-lived ROS. The longer wavelength peaks represented reactions of lipid peroxides with other amino acids. Such reactions between lipids and nitrogen may contribute to the decreasing $\mathrm{C}: \mathrm{N}$ ratio of PDOM (Fig. 1a) and the decreasing proportion of nitrogen appearing as ammonium (Fig. 1b).

Many ROS, such as hydrogen peroxide, have short lifetimes in solution, possibly limiting the extent of these reactions. However, entrapment within plant membranes can stabilize some ROS, such as singlet oxygen, extending in time their possible influence on various reactions (Rontani 2001).

From an optical perspective, irradiation resulted in the net loss from the overall suspension of particulate chromophores absorbing at visible wavelengths and accumulation of dissolved ones absorbing at UV wavelengths. Chromophoric material shifted from the particulate to the dissolved phase to a much greater degree than the shift in mass. This photobleaching of the solid phases was primarily due to destruction of solid phase chromophores, though the production of CDOM (Fig. 2) and FDOM indicates that photodissolution accounted for some of the bleaching. Phytopigment chromophores strongly lost from the solid phase did not, however, appear in recognizable form in solution. The overall spectral changes, primarily replacement of pigment and diene peaks by featureless background, also indicate a compositional progression from biochemicals to humified materials.

The EHAA results offer insight into processes that affect bioavailability of the particulate detritus. The decrease in the EHAA:THAA ratio with decay indicates decreased bioavailability with detritus age; proteinaceous material apparently became packaged in some fashion that reduced its accessibility by proteolytic enzymes. This packaging may have been no more than formation of bacterial biomass that resisted in vitro enzyme attack. Alternatively, it may have resulted from chemically induced encapsulation of membrane proteins, such as autooxidative cross-linking of lipids during the decay process (Versteegh et al. 2004; Pancost et al. 2008). Zamora and Hidalgo (2001) showed 
that reaction with lipid oxidation products could protect protein against proteolytic attack. Irradiation apparently reversed any such packaging in our experiment, suggesting a net increase of the biological availability of the settling particulate fraction that is not photodissolved. Changes in bioavailability upon irradiation can be complex (Tranvik and Bertilsson 2001), and the change that we observed may not be a general phenomenon.

Extent of reaction - Our results are demonstrative only, in that photodissolution extents in the field could easily be greater or smaller than in our experiments, depending on light exposure and other factors. For example, the photodissolution extent in our experimental configuration may have been limited by solubility considerations, which might be ameliorated if the ratio of particulate to dissolved organic matter was changed by particle sinking or microbial uptake of the DOM. In other work, we found that the PDOM from these algal membranes is highly available to microbial uptake (L. Mayer unpubl. data), and Miller and Moran (1997) showed that alternating episodes of photochemistry and microbial uptake markedly enhance metabolic loss of DOM. In addition, we used full-spectrum sunlight, which would show preferential attenuation of UV wavelengths, and presumably less effectiveness, with water depth.

Pigment profiles with depth can act as tracers for algal membrane photochemical reactions in oceanic water columns. If the other photochemical reactions that we studied in the field scale to pigment loss to the same extent as in our laboratory results, then we can use the results of Cuny and Rontani (1999) and Cuny et al. $(1999,2002)$ to gauge possible field importance of this reaction. These authors found that ratios of pigment photodegradation products to intact pigments indicate that the bulk of pigments were being photodegraded in various oceanic water columns, especially clearer ones. In our kinetics experiment, 29\% of the chlorophyll was lost by $0.5 \mathrm{~h}$ and virtually all of it lost by $4 \mathrm{~h}$. Accompanying the pigment losses at these time points were photodissolution extents of $5 \%$ and $15 \%$ of the original POC to DOC and DIC. Suspensions that lost all of their chlorophyll continued to photodissolve PDOM in our experiments, and the same may be true of particles that have lost all of their chlorophyll in the field. Thus this scaling exercise suggests that photodissolution extents may be $5-15 \%$ or even greater in such environments. In the water column these reactions will depend strongly on factors controlling particle nature and residence time in the irradiated upper waters, which in turn are strongly affected by autotrophic and heterotrophic planktonic community structure.

Of course, algal detritus decays quickly via microbial attack even in the absence of light. Photodissolution of algal detritus may, however, bias the decay toward the upper, lit part of water columns by changing some of the organic matter to a form that is not susceptible to settling. We have also found that PDOM from algal detritus is easily metabolized by microbes (Mayer unpubl. data). In the process it also biases trophic transfer away from particle-feeding animals and toward the osmotrophic microbial community. The rate of decomposition of algal detritus typically slows down with increasing decay state, or age, of the detritus (Middelburg 1989). Because our experiment shows that photochemical reactivity appears to increase with increasing decay, the importance of light may increase with detritus age

Our results extend from sediments to planktonic detritus the finding that sunlight can cause significant dissolution of organic matter and provide a potential explanation for the photodissolution of relatively young organic matter from marine sediment suspensions. To the extent that this reaction is important in oceanic water columns, settling of OM to deeper heterotrophic populations will be reduced, and the PDOM will be maintained at shallower depths and shift OM metabolism toward microbes. Color will also be left behind in the upper ocean as chromophores photodissolve and photobleached particles settle out. The efficacy of this upper ocean increase in recycling efficiency will be favored at lower latitudes. Likely other changes will occur in the solid phase that affect subsequent chemical and biological processing. Oxygen-dependent processes imply photosensitization reactions as an important component of these changes, driven by a variety of photolabile compounds. Future work should seek to couple optical properties of algal detritus with those of water columns, address variations in photoreactivity of different algal substrates, assess interactions between the photochemistry of algal debris and other particles or dissolved organic matter, and examine reactions involving ROS derived from these particulates.

\section{Acknowledgments}

This work was funded by National Science FoundationChemical Oceanography. We thank the reviewers and associate editor for helpful comments.

\section{References}

Anesio, A. M., L. J. Tranvik, and W. Graneli. 1999. Production of inorganic carbon from aquatic macrophytes by solar radiation. Ecology 80: 1852-1859.

Babin, M., And D. Stramski. 2002. Light absorption by aquatic particles in the near-infrared spectral region. Limnol. Oceanogr. 27: 911-915.

Blokhina, O. B., K. V. Fagerstedt, and T. V. Chirkova. 1999. Relationships between lipid peroxidation and anoxia tolerance in a range of species during post-anoxic reaeration. Physiolog. Plantar. 105: 625-632.

Brown, M. R. 1991. The amino-acid and sugar composition of 16 species of microalgae used in mariculture. J. Exp. Mar. Biol. Ecol. 145: 79-99.

Corongiu, R. P., and A. Milia. 1983. An improved and simple method for determining diene conjugation in autoxidized polyunsaturated fatty acids. Chem.-Biol. Int. 44: 289-297.

Creed, D. 1984. The photophysics and photochemistry of the near-UV absorbing amino acids I. Tryptophan and its simple derivatives. Photochem. Photobiol. 39: 537-562.

Cuny, P., J.-C. Marty, J. Chiaverini, I. Vescovali, D. Raphel, AND J.-F. Rontani. 2002. One-year seasonal survey of the chlorophyll photodegradation process in the Northwestern Mediterranean sea. Deep Sea Res. II 49: 1987-2005. 
, J.-C. Romano, B. Beker, and J.-F. Rontani. 1999. Comparison of the photodegradation rates of chlorophyll chlorin ring and phytol side-chain in phytodetritus: Is the phytyldiol versus phytol ratio (CPPI) a new biogeochemical index? J. Exp Mar. Biol. Ecol. 237: 271-290.

- AND J.-F. RonTANi. 1999. On the widespread occurrence of 3-methylidene-7,11,15-trimethylhexadecan-1,2-diol in the marine environment: A specific isoprenoid marker of chlorophyll photodegradation. Mar. Chem. 65: 155-165.

Dillon, J., And A. SPector. 1980. A comparison of aerobic and anaerobic photolysis of lens protein. Exp. Eye Res. 31: 591-599.

Frankel, E. N. 1998. Lipid oxidation. Oily Press.

Girotti, A. W. 2001. Photosensitized oxidation of membrane lipids: Reaction pathways, cytotoxic effects, and cytoprotective mechanisms. J. Photochem. Photobiol. B: Biol. 63: 103-113.

Green, S. A., And N. V. Blough. 1994. Optical absorption and fluorescence properties of chromophoric dissolved organic matter in natural waters. Limnol. Oceanogr. 39: 1903-1916.

Hammes, F. A., S. Meylan, E. Salhi, O. Köster, T. Egli, and U. vON GUNTEN. 2007. Formation of assimilable organic carbon (AOC) and specific natural organic matter (NOM) fractions during ozonation of phytoplankton. Water Res. 41: 14471454.

Heath, R. L., And L. Packer. 1968. Photoperoxidation in isolated chloroplasts. II. Role of electron transfer. Archiv. Biochem. Biophys. 125: 850-857.

Inoue, K., T. Matsuura, And I. Saito. 1982. Photogeneration of superoxide ion and hydrogen peroxide from tryptophan and its photooxidation products: The role of $3 \alpha$-hydroperoxypyrrolidinioindole. Photochem. Photobiol. 35: 133-139.

Kanias, T., K. Wong, and J. P. Acker. 2007. Determination of lipid peroxidation in desiccated red blood cells. Cell Preserv. Technol. 5: 165-174.

Kieber, R. J., L. H. Hydro, and P. J. Seaton. 1997. Photooxidation of triglycerides and fatty acids in seawater: Implication toward the formation of marine humic substances. Limnol. Oceanogr. 42: 1454-1462.

- R. F. Whitehead, and S. A. Skrabal. 2006. Photochemical production of dissolved organic carbon from resuspended sediments. Limnol. Oceanogr. 51: 2187-2195.

Kikugawa, K., And M. Beppu. 1987. Involvement of lipid oxidation products in the formation of fluorescent and cross-linked proteins. Chem. Phys. Lipids 44: 277-96.

- T. Kato, And A. Hayasaka. 1991. Formation of dityrosine and other fluorescent amino acids by reaction of amino acids with lipid hydroperoxides. Lipids 26: 922-929.

López-Ayerra, B., M. Antonia Murcia, and F. GarciaCARMONA. 1998. Lipid peroxidation and chlorophyll levels in spinach during refrigerated storage and after industrial processing. Food Chem. 61: 113-118.

LORENZEN, C. J. 1967. Vertical distribution of chlorophyll and phaeo-pigments: Baja California. Deep Sea Res. 14: 735-745.

Måns, C., T. Denward, and L. Tranvik. 1998. Effects of solar radiation on aquatic macrophyte litter decomposition. Oikos 82: $51-58$.

Marchand, D., J. C. Marty, J. C. Miquel, and J.-F. Rontani. 2005. Lipids and their oxidation products as biomarkers for carbon cycling in the northwestern Mediterranean Sea: Results from a sediment trap study. Mar. Chem. 95: 129-147.

—, AND J.-F. Rontani. 2001. Characterization of photooxidation and auto-oxidation products of phytoplanktonic monounsaturated fatty acids in marine particulate matter and recent sediment samples. Org. Geochem. 32: 287-304.
Mayer, L. M., L. L. Schick, T. S. Bianchi, and L. A. Wysocki. 2009. Photochemical changes in chemical markers of sedimentary organic matter source and age. Mar. Chem. 119: 123-128.

AND T. LODER. 1999. Dissolved protein fluorescence in two Maine estuaries. Mar. Chem. 64: 171-179.

, T. Sawyer, C. Plante, P. A. Jumars, and R. L. SELF. 1995. Bioavailable amino acids in sediments: A biomimetic, kinetics-based approach. Limnol. Oceanogr. 40: $511-520$.

, K. Skorko, and E. Boss. 2006. Photodissolution of particulate organic matter from sediments. Limnol. Oceanogr. 51: 1064-1071.

Middelburg, J. J. 1989. A simple rate model for organic matter decomposition in marine sediments. Geochim. Cosmochim. Acta 53: $1577-1581$.

Miller, W. L., AND D. R. Kester. 1988. Hydrogen peroxide measurement in seawater by ( $p$-hydroxyphenyl) acetic acid dimerization. Anal. Chem. 60: 2711-2715.

- AND M. A. Moran. 1997. Interaction of photochemical and microbial processes in the degradation of refractory dissolved organic matter from a coastal marine environment. Limnol. Oceanogr. 42: 1317-1324.

Mopper, K., X. Zhou, R. J. Kieber, D. J. Kieber, R. J. Sikorski, AND R. D. Jones. 1991. Photochemical degradation of dissolved organic carbon and its impact on the oceanic carbon cycle. Nature 353: 60-62.

Moran, M. A., AND R. G. ZEPP. 1997. Role of photoreactions in the formation of biologically labile compounds from dissolved organic matter. Limnol. Oceanogr. 42: 13071316.

Nelson, J. R. 1993. Rates and possible mechanism of lightdependent degradation of pigments in detritus derived from phytoplankton. J. Mar. Res. 51: 155-179.

- AND C. Y. RoBeRTSON. 1993. Detrital spectral absorption: Laboratory studies of visible light effects on phytodetritus absorption, bacterial spectral signal, and comparison to field measurements. J. Mar. Res. 51: 181-207.

North, J. A., A. A. Spector, And G. R. Buettner. 1994. Cell fatty acid composition affects free radical formation during lipid peroxidation. Am. J. Physiol. Cell Physiol. 267: C177-C188.

Osburn, C. L., And D. P. Morris. 2003. Photochemistry of chromophoric dissolved organic matter in natural waters, p. 185-217. In E. W. Helbling and H. Zagarese [eds.], UV effects in aquatic organisms and ecosystems. Royal Soc. Chem.

Pancost, R. D., J. M. Coleman, G. D. Love, A. Chatzi, I. Bouloubassi, AND C. E. SNAPE. 2008. Kerogen-bound glycerol dialkyl tetraether lipids released by hydropyrolysis of marine sediments: A bias against incorporation of sedimentary organisms? Org Geochem. 39: 1359-1371.

Parsons, T. R., Y. Maita, and M. Lalli. 1984. A manual of chemical and biological methods for seawater analysis. Pergamon.

Refsgand, H. H. F., L. Tsai, and E. R. Stadtman. 2000. Modifications of proteins by polyunsaturated fatty acid peroxidation products. Proc. Natl. Acad. Sci. 97: 611616.

Robinson, J. M., M. G. Smith, And M. GibBs. 1980. Influence of hydrogen peroxide upon carbon dioxide photoassimilation in the spinach chloroplast. I. Hydrogen peroxide generated by broken chloroplasts in an "intact" chlorophyll preparation is a causal agent of the Warburg Effect. Plant Physiol. 65: 755-759. 
RontANI, J.-F. 1998. Photodegradation of unsaturated fatty acids in senescent cells of phytoplankton: photoproduct structural identification and mechanistic aspects. J. Photochem. Photobiol. A. 114: 37-44.

. 2001. Visible light-dependent degradation of lipidic phytoplanktonic components during senescence: A review. Phytochemistry 58: 187-202.

Soohoo, J. B., AND D. A. Kiefer. 1982. Vertical distribution of phaeopigments - II. Rates of production and kinetics of photooxidation. Deep Sea Res. 29: 1553-1563.

Sommaruga, R., I. Obernosterer, G. J. Herndl, and R. Psenner. 1997. Inhibitory effect of solar radiation on thymidine and leucine incorporation by freshwater and marine bacterioplankton. Appl. Environ. Microbiol. 63: 4178-4184.

TArr, M. A., W. Wang, T. S. Bianchi, and E. Engelhaupt. 2001. Mechanisms of ammonia and amino acid photoproduction from aquatic humic and colloidal matter. Water Res. 35: 3688-3696.

Tranvik, L. J., and S. Bertilsson. 2001. Contrasting effects of solar UV radiation on dissolved organic sources for bacterial growth. Ecol. Lett. 4: 458-463.

Verhagen, J., A. A. Bouman, J. F. G. Vliegenthart, and J. BoldingH. 1977. Conversion of 9-D- and 13-L-hydroperoxylinoleic acids by soybean lipoxygenase-1 under anaerobic conditions. Biochim. Biophys. Acta 18: 114-120.
Versteegh, G. J. M., P. Blokker, G. D. Wood, M. E. Collinson, J. S. Sinninghe Damsté, and J. W. De Leeuw. 2004. An example of oxidative polymerization of unsaturated fatty acids as a preservation pathway for dinoflagellate organic matter. Org. Geochem. 35: 1129-1139.

Yentsch, C. S., And C. A. Reichert. 1962. The interrelationship between water-soluble yellow substances and chloroplastic pigments in marine algae. Bot. Mar. 3: 65-74.

ZAFIRIOU, O. C. 1977. Marine organic photochemistry previewed. Mar. Chem. 5: 497-522.

. 2002. Sunburnt organic matter: Biogeochemistry of light-altered substrates. Limnol. Oceanogr. Bull. 11: 69-74.

Zamora, R., AND F. J. Hidalgo. 2001. Inhibition of proteolysis in oxidized lipid-damaged proteins. J. Agric. Food Chem. 49: 6006-6011

Associate editor: Stephen P. Opsahl

Received: 17 December 2008 Accepted: 14 May 2009

Amended: 20 May 2009 